\title{
Intermediate Mitosis-Karyorrhexis Index
}

National Cancer Institute

\section{Source}

National Cancer Institute. Intermediate Mitosis-Karyorrhexis Index. NCI Thesaurus. Code C118957.

An index used in neuroblastic tumors indicating the presence of between 100 and 200 mitoses and karyorrhexis per 5,000 cells. 